\title{
Development of the Knowledge Organization
}

\author{
Beáta Furmannová1,* , Radovan Furmann ${ }^{1}$ \\ 'University of Žilina, Faculty of Mechanical Engineering, Department of Industrial Engineering, Univerzitná 1, 010 26 Žlina, Slovak Republic
}

\begin{abstract}
Organizational development is an increase the effectiveness and viability of the organization through application of knowledge of behavioural sciences. The aim is change of formal and informal structures, processes, work, skills and performance of people, and application of new technologies. Organizational development is used as an overall framework for permanent organizational change and is related to change management and innovation implementation. Organizational development is a purposeful process of change that aims to create an organizational environment for a prosperous knowledge organization. Therefore, it is important to look at the organization from different perspectives that we can visualize in the form of organization models. Visualization of organizational models helps to determine what is possible and purposeful to change directly in the organization and what is no longer possible. In engineering, this is an image simplified by organizations.
\end{abstract}

Keywords: organization, organizational development, vitality, organizational universe, key organization activities.

\section{Introduction}

A purposeful development of the organization is associated with change management. Organizations have different goals, philosophy and levels of moral, and exist in a particular environment. At the beginning it is appropriate to gain a top view by using of existing organization models. If the changes are related to the transition of an existing company to a knowledge-based company, i tis necessary to create an internal working environment in which knowledge can be created, discovered, captured, shared, extracted, verified, transmitted, modified, adapted and applied. In terms of the company's management it is interesting to know what are the possibilities of organization development, what development concepts are approved in purposeful creation of a working environment that enables to prepare people for the future.

In general, we understand the success of organization development as an achievement of required result of some effort. We can achieve a success in every area where we can do something. When we are talking about the successful organization development, we mean a conscious action with a respect of factors that have a significant impact on achieving the desired result. It is possible to formulate organizational success factors (Figure 1).

This means that it is necessary to take care not only of performance goals but also look at the development of important internal organization elements that is needed to compliance with the development of important elements of external environment. It is important to respect the personality of individuals and to adapt behaviour to the conditions of creating good and functional relationships. And it is also necessary to use the synergy effect of good cooperation between people who have common goals and want to achieve them by joint effort. 


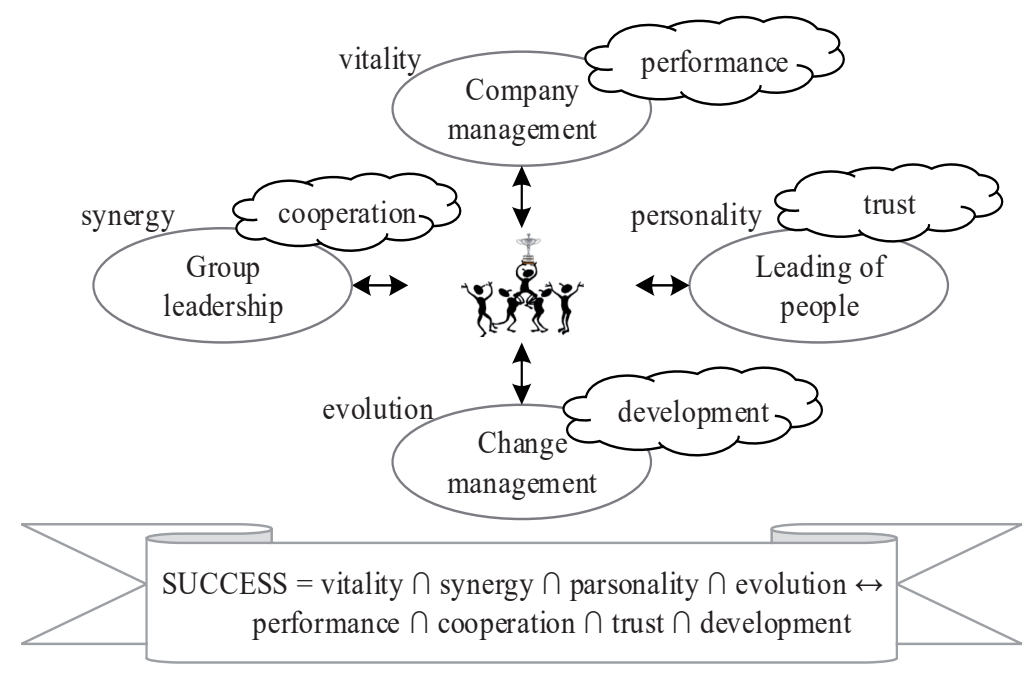

Fig. 1: Factors of organizational development success.

\section{Organizations development}

Organizational development is a goal-oriented process of change with the purpose of creation an organizational environment for a prosperous knowledge society. At the beginning it is important to be clear about what is possible and practical to change directly and what directly change is not possible. Helpful may be different views on the organization which result is simplified reality of organization environment visualized in the form of organizational models.

This is explained in the following four organization models:

\section{$\checkmark$ Organization as a social-technical system.}

$\checkmark$ Organization vitality.

$\checkmark$ Organizational universe.

$\checkmark$ Model of key organization activities.

\section{Organization as a social-technical system}

This model is the result of applying a systematic approach to analyse the organization. It offers a specification of the organization's elements belonging to the three different subsystems of the organization.

If the analysed object is very complicated, we describe it with the use of abstraction and systematic approach. In the case of an organization it means that we are looking for purposeful sets of elements that interact with each other and with the environment. For a concise and clear expression of the essential elements of any organization, there was a model of organization description created as a social-technical system in which it is useful to distinguish the technical, social and cultural subsystem. Model (Prokopenko, 1999) is illustrated in tab. 1.

Technical subsystem contains two elements that can be relatively easily changed by direct managerial interventions. Increasing the organization's performance through procurement more powerful technical equipment and more efficient technologies and globally investing can be costly. Correct workflow setup is also matter of technical subsystem and its changes are also significant cost item. Changes in this subsystem are normally supported by substantive arguments as a result of rational decision-making.

Social subsystem contains three elements relating to human labour organization. The choice of the organizational structure, as well as setting of remuneration system, communication system and decision-making processformsorganizationelement that predicates of organization arrangement. Individuals, groups, relationships and leadership create in each organization unique societies that are extremely sensitive to any changes. Social subsystem is completed by a set of job positions and tasks that belong to individual functions within the organization structure. All three elements of social subsystem are essentially interconnected. Such a change such as an introduction and full-area application of a teamwork in the organization in order to create knowledge society mainly relate to changes in the social subsystem.

Cultural subsystem contains two elements that carry information about the reason for existence 
Tab. 1: Organization as a social-technical system [6].

\begin{tabular}{|l|l|l|}
\hline \multicolumn{2}{|l|}{ Organization - System elements } & 3 subsystems \\
\hline 1 & IDENTITY - the reason for the existence of an organization & \multirow{2}{*}{ cultural } \\
\hline 2 & POLICY, STRATEGY, PROGRAMS - rules, rules, principles, guidelines & \\
\hline 3 & TOTAL STRUCTURE - arrangement & \multirow{2}{*}{ social } \\
\hline 4 & PEOPLE (individuals, groups, relationships, leadership) & \multirow{2}{*}{ technical } \\
\hline 5 & FUNCTIONS (jobs, tasks) & \\
\hline 6 & WORKING PROCESSES, workflow & \\
\hline
\end{tabular}

of the organization and about rules that are set in the organization to enable the organization to work and guide the behaviour of its employees. As a result of efforts to formulate the most appropriate definition of organization culture is a significant number of definitions. Organization culture is usually understood very widely - as a set of values, symbols, attitudes, ethical origins, assumptions and perspectives that influence on employees' behaviour to each other and to the external environment. Organization culture provides employees a sense of identity and core values in an organization that are recognized and sustained. The culture of the organization is represented by actions, exerted behaviour, not by words. In the case of knowledge-based society, the cooperation, mutual trust and knowledge sharing are of values that influence the creation of behaviour and action rules.

Understanding the patterns of work and cooperation between individuals and groups is a prerequisite of using the knowledge potential of individuals and organizations. And that's what it's all about, learning to share knowledge for the benefit of all of us. In a global scale, if the results of scientific work are available, if experiences that are subject of interest are shared in scientific and social communities, the benefit of everyone can be expected. If collaborative organizations can share knowledge for all stakeholders, if there are supportive mechanisms for sharing knowledge, benefit for all stakeholders can be also expected.

Sharing is a normal way of achieving a common goal based on mutual trust and cooperation, so it is needed to start with serious creation of organizational environment that supports work of teams of various types and specifications. It is appropriate to start with implementation of teams, where can everyone be aware of their contribution to achieving the common goal by their thinking, behaviour, knowledge and work. And it is also appropriate to start building a knowledge-based society by supporting a teamwork.

\section{Organization vitality}

The theory of vitality provides an organization model that emphasizes the conditions for keeping the viability of organizational units. This model helps to understand the patterns of organ survival and helps to specify requirements for team composition. Vitality, viability in individuals and organizations is demonstrated by the ability to react quickly enough to impulses and changes.

According to Plamínek (2011) ability to sustain long term success can be named as vitality. Success is considered as a state when expected result has been achieved.

To achieve vitality, four conditions must be met, which can be clarified through following questions:

$\checkmark$ Usefulness: Do we have something to offer? Do we know why and to whom?

\section{$\checkmark$ Effectiveness: Inn't it too expensive?}

$\checkmark$ Stability: Can we cope with changes and difficulties?

$\checkmark$ Dynamics: Can we manage changes and influence development?

The theory of vitality can be used in several cases. For example, if there is no interest in something, we should analyse where and for who it can be useful before we start to improve it. The theory of vitality is illustrated by the author as a pyramid of vitality that highlights the sequence of viability reassessment of any particular living object. If we realize that survival in the real world always depends on the availability of resources, and we want to highlight this fact, we will extend the vital pyramid by the new level and name it the source (Figure 2).

To verify the meaningfulness of the vitality pyramid, it is good to verify it on an example of a living organism. The easiest way is to imagine 
yourself as an object of investigation and to verify the correctness of these five signs of human vitality. Experiences say that if a group of people think about the vital pyramid, each member of the group, based on his knowledge and experiences, is able to generate a unique example of the interpretation of vitality conditions. If group members are willing to share their views with others, it is the best way to find the common ways of using this view to keep the viability of individuals and of working groups and organizations.

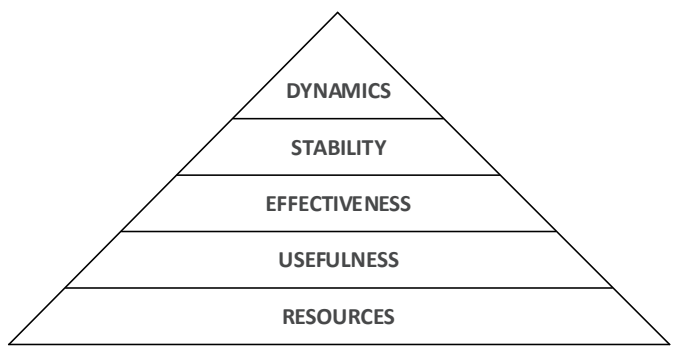

Fig. 2: Vitality pyramid [7].

If we consider the organization as a living organism, we can see that it needs sufficient resources (human, information, material, financial) to keep its vitality. Having resources is necessary but not sufficient. Usefulness means that working team needs to be focused on achieving the results leading to the goal. Efficiency means that team should focus not only on achieving the goal, but also on the process and the ways to solve the problem with the lowest resource consumption. Stability indicates that team has control mechanisms to ensure certainty that routing and processes are set up correctly. Dynamics suggests that team has the ability to risk, if it can bring new solutions.

We need viable individuals, organizations, viable working groups, teams and organizations. The theory of vitality can be used in planning and change management, as it shows very clearly what should not be forgotten. For example, when we are building new team, we want to ensure the diversity of knowledge and motivational types in the team so that it brings all the signs of vitality.

\section{Organizational universe}

This model (Johnes, 1981) provides an overview of the links between the reason for the existence of a specific organization, its objectives, structure, and important elements of the environment in which it operates. For the understanding of the organizational universe, it is recommended to proceed from the whole to the structures and processes that need to be monitored before the change activities begin. It allows you to see what can be changed in the organization, if we want to achieve a high degree of cooperation and coordination. Fig. 3 emphasizes not only the links of "values $\rightarrow$ objectives $\rightarrow$ structure $\rightarrow$ atmosphere", but also highlights those elements of the organization's external environment that have a significant impact on the formation of organizations.

Values - the core of any human organization consists of the values, of the philosophy that defines the reason of its existence and of the purpose for which the organization was founded. Unfortunately, the values on which the organization was originally founded are often lost in everyday hurry. In case these values are not accepted together, lack of consensus will generate tensions that can disrupt the efficiency of the organization. To maintain organizational values, the manager must monitor the range in which people defend common premises, philosophies, and goals. However more important is, that particularly managers have to demonstrate value-oriented behaviour.

Goals - the goal-setting process needs to be highlighted whenever possible. Members of the organization must be part of this process if they should stand for it. For managers, this means that they have to pay attention to participation when setting goals. Meaningful participation leads to a feeling of co-responsibility. This makes feeling of influence that generates a sense of psychological ownership and leads to engagement. Engagement is developed in individuals as a result of their perception of their influence. Tasks are specified goals. When managing changes, it is important to align the required results with the values and resources that are available to meet the tasks in the organization.

Structure - the organizational structure is mostly represented as a graphic record illustrating the hierarchy of the organization's departments, highlighting the areas of operation and their relationships. In fact, it is necessary to establish not only relations between superiors and subordinates, but also ways of communication, procedures for decision-making and solution of system problems, rules or guidelines for the organization's behaviour, 
as well as a remuneration system for achieving goals. All these systems together form the structure of the organization.

Atmosphere - is the result and determinant for the behaviour of individuals and groups within the structure. Managers have to realize that the organizational atmosphere and attitudes of others cannot be directly controlled or changed. The attitudes can be seen as behaviour rationalization. If we change behaviour (by remuneration system, for example), the attitudes will eventually adjust. Trust will not be created by talking about it, rather the opposite. Trust is the result of achieving success together with common goals. Managers must show sensitivity to the consequences of their behaviour on the atmosphere.

Environment-herewe understand theelements of the external organizational environment, linked to the organization. Although this environment is different for each organization, organizations share some global aspects, for example, the energy resources that affects almost all human organizations. Good cohabitation with the environment requires the flexibility of an internal structure able to confront with unpredictable situations as well as sensitivity to the environment.

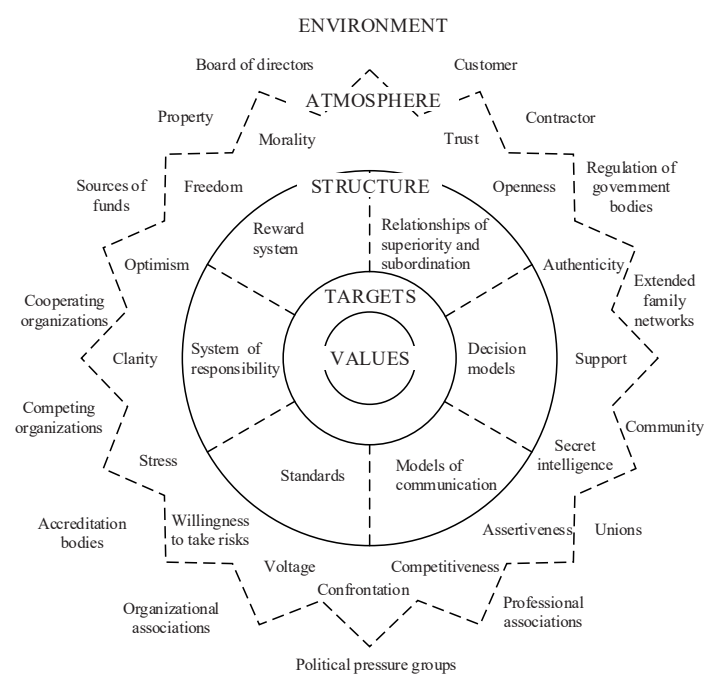

Fig. 3: Organizational universe [3].

The organizational universe model shows the sense of knowing a set of values that defines the reason for the organization existence, and understanding the purpose for which the organization was based.
It shows how the goals are formed from this core, the rules of the organization's internal functioning and what elements of the external environment effect on the organization's life.

\section{Model of key organization activities}

This model allows a visualization of the bonds for organization's key activities, highlighting the need to share the knowledge of those involved in achieving the organization's common goals. We know that each organization has a reason for existence, own customers, suppliers, and often competitors as well.

There are several options for describing a set of key organizational activities through which is realized customer-determined production. A simple model of the organization's key activities (fig. 4) serves to visualize those professional activities through which the production of most viable organizations is realized.

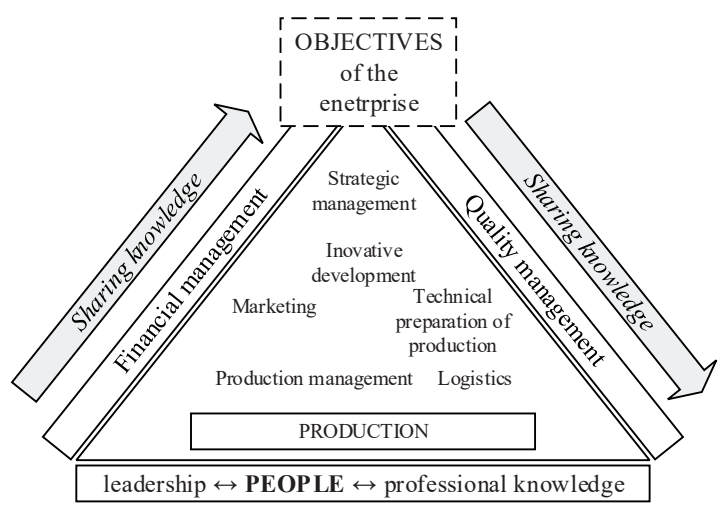

Fig. 4: Model of key activities in production organization [7].

The model highlights the need to share knowledge. The framework of strategic decisions mainly concerns the sharing of vision, values and long-term goals. Strategic decisions include the choice of the organizational development program, the specific organizational structure and the form as well as scope of teamwork implementation. In the organization hierarchy, it is necessary to seek for knowledge sharing not only from top to bottom but from bottom to top as well. Such sharing of knowledge aren't a matter of course at all. It requires considerable advancement in the organization's thinking and management at all hierarchical levels. Therefore, the knowledge sharing rate is an indicator of the organization's excellence, demonstrating the organization's readiness for the future. 
The experience of many organizations confirms that it is very difficult to be a flexible organization without work of project teams, improvement teams or production teams. Dynamics of change is so great that a standard way of managing systems and processes in an organization is not sufficient. Therefore, it is necessary to focus on the benefits of the well-established development programs of organizations, and their impact on retention of the required flexibility and performance of the organization. [3]

\section{Knowledge society}

According to the synonym dictionary of the Slovak language, knowledge and skills are synonymous. We can see a difference if we compare the following definitions. Skill is acquired findings by learning i.e. remembered and understandable facts or relationships between facts (such as concepts, rules, guidelines, laws, formulas, marks, etc.). Knowledge is essentially a meaningful interconnection that humans creates in the mind between information and its use in a special situation, based on skills and capability to use it, previous experience, mental models, relationships, values, the principles by which people live and believe.

In an effort to briefly express what to understand under the concept of knowledge is used sometimes the definition of Concise Oxford Dictionary, which reads: Knowledge is the skill received from experience.

Practitioners (Collison, 2005) say that knowledge are more than know-how. In addition to answering the question how, they also answer questions why, what, who, where and when:

$\checkmark$ HOW (know-how) relates to the processes, procedures, methods and tools, that are used to create something.

$\checkmark \underline{W H Y}$ relates to key findings, enable to understand the context of your role and the importance of your activities, promotes morale and engagement of the stakeholders.

$\checkmark$ WHAT includes the facts needed to perform the task and information needed for decision making.

$\checkmark \underline{\text { WHO }}$ has knowledge of relationships, contacts, and people, which we can ask for help. The verbal link "I know about someone who could ..." is commonly used and often unknowingly creating this type of knowledge.

$\checkmark \underline{\text { WHERE }}$ is the special ability of some people to orient themselves and find the right information.

$\checkmark$ WHEN involves a special sense of timing, knowing the most appropriate time when to do something, when to make a decision and

\section{when to end up with something.}

Practice says that the systematic building of a knowledge-based society is a long-term process and today we are at the beginning. That we are at the beginning signals the gradual creation of a common vocabulary that is needed to describe the systems, processes, elements and bonds forming the knowledge society.

It is useful for team work to be well informed about knowledge management for a number of reasons. One reason is that teams are the action units of an organization whose collaboration brings not only required results and new expertise, but also new knowledge and experience of collaborative processes.

Another reason is the cognition that the common goal, the atmosphere of cooperation and the mutual trust of team members naturally promote the sharing of knowledge in the team. Let's say that sharing knowledge in the team is the unconscious competence of the team. We speak about unconscious competence when people create and share knowledge naturally as part of their work without considering it as an extra task, while the leadership of the organization and the established processes only support this state.

To gain an integrated and comprehensive view of teamwork in the context of management of knowledge, it will well serve the concept of practical knowledge management from the world learning organizations (Collison, 2005). This concept allows you to get acquainted with options like:

$\checkmark$ increase business performance by sharing information and by transfer of proven methods,

$\checkmark$ improve team work through better communication and education,

$\checkmark$ build an effective information delivery system.

Knowledge management refers to the acquisition, creation, sharing and use of knowledge. Includes explicit and tacit knowledge. It is based on the knowledge that it is not enough to know AKO (know-how) but also to know WHO, WHY and WHEN. It concerns people, working communities who maintain knowledge about specific area and share what they know, build on it and adapt it for their own use. From the point of function, it can connect areas of learning and development of organizations (processes), management of human resources (people) and information technologies (technologies). Between basic elements of successful knowledge management include a 
reliable common technology infrastructure that enables knowledge sharing. Linking people who have knowledge and they are willing to share, ask and listen. Introduced processes to simplify sharing, validating, and extracting knowledge.

For team work, it is useful to know that there are two ways to get the knowledge needed to solve the problem. Find out what others know - we'll find people and talk to them, and it will often bring us to the network of a working community. Find out what is known - what is already recorded in the form of certain information that we could use. Keeping in mind the recency, the recorded one tends to become obsolete.

When we talk about management, we usually ask ourselves what can be done with the command and what can only be influenced. The sequence of these activities suggests that only what is possible and necessary is to create an organizational environment in which knowledge can be created, discovered, captured, shared, extracted, verified, transmitted, received, edited and applied.

In order to create the necessary environment, we will need the right conditions (a reliable common infrastructure of the organization), resources (a common model, tools and processes), activities (when people instinctively search, share and use knowledge) and leadership (inspiring learning and sharing knowledge).

For organization, one of the paths is to set up a knowledge management team to find a suitable knowledge management model and to manage the process of its implementation. Therefore, it is important to look for what already works within the organization (find a few heroes and show what they have done). Explore the world outdoors and look for successful methods (these must be tested in condition of organization). Focus on a few key tools and promote it. Do it all easily and do not introduce a "new language". Work intensively on a number of key areas that can show benefits of the knowledge management. Explore existing business processes and "infect" them with their knowledge management.

\section{Conclusions}

Understanding the regularities of organizational development is possible if we can see companies as living organisms that seek to maintain vitality in the long term, use synergy, respect the personality of human as well as respect the patterns of evolution. Those who are able to do this can deliver the desired performance, promote collaboration, create the conditions for establishing and maintaining trusting relationships, and support the development of individuals, teams and the whole organization. Understanding such a complex organism as a company is possible through a variety of organizational models that simplify the image of the company. Different viewing angles lead to different models, while the purpose of simplification is for all these models mutual - to allow the full range of conditions for creating and maintaining high-performance teams in the organization. In organizations it is necessary to know the current state and know how to reach the future state, this allows to understand the need for changes. This is true in many areas of engineering (both in terms of innovation process management, quality assurance and resource management).

\section{Acknowledgments}

This publication is the result of the Project implementation: Competency Centre for Knowledge technologies applied in Innovation of Production Systems in Industry and Services, ITMS: 26220220155, supported by the Research \& Development Operational Programme funded by the ERDF.

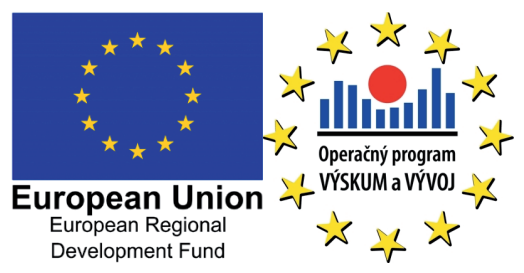

\section{References and Notes}

[1] COLLISON, Ch. - PARCEL, G.: Knowledge Management Praktický manažment znalostí z prostredia popredných svetových učiacich sa organizácií. Computer Press, Brno 2005

[2] GREGOR, M., GRZNÁR, P., PEDAN, M., CUDRÁKOVÁ, M.: Knowledge in healthcare. In: Annals of DAAAM. Proceedings of the 26-th DAAAM International symposium on intelligent manufacturing and automation. Vienna: DAAAM International Vienna, 2016, ISBN 978-3-902734-07-5, p. 1115-1121.

[3] JOHNES, J.E., PFEIFFER, J.W.: The organizational universe. In. The 1981 Annual Handbook for Group Facilitators. San Diego: University Associates 1981, ISBN 9780883900031, p. 296.

[4] MIČIETA, B., GAŠO, M., KRAJČOVIČ, M.: Innovation perfor- 
mance of organization. In: Communications - Scientific letters of the University of Žilina. Vol. 16, no. 3A (2014), ISSN 1335-4205, p. 112-118.

[5] PLAMÍNEK, J.: Vedení lidí, týmů a firem. Praktický atlas managementu, 4. zcela přepracované vydání, Grada Publishing, 2011, ISBN 978-80-247-3664-8, s. 160.

[6] PROKOPENKO, J., NORTH, K.: Management produktivity a jakosti - modulový program. Modul 8: Managemet organizačních změn. Svazek 9. ILO a APO. Česká společnost pro jakost, Praha, 1999, ISBN 80-02-01473-1.

[7] TUREKOVÁ, H., FURMANNOVÁ, B., GAŠO, M.: Tímová práca. EDIS - Žilinská univerzita v Žiline, 2018, ISBN 978-80-5541504-8, 261 strán.

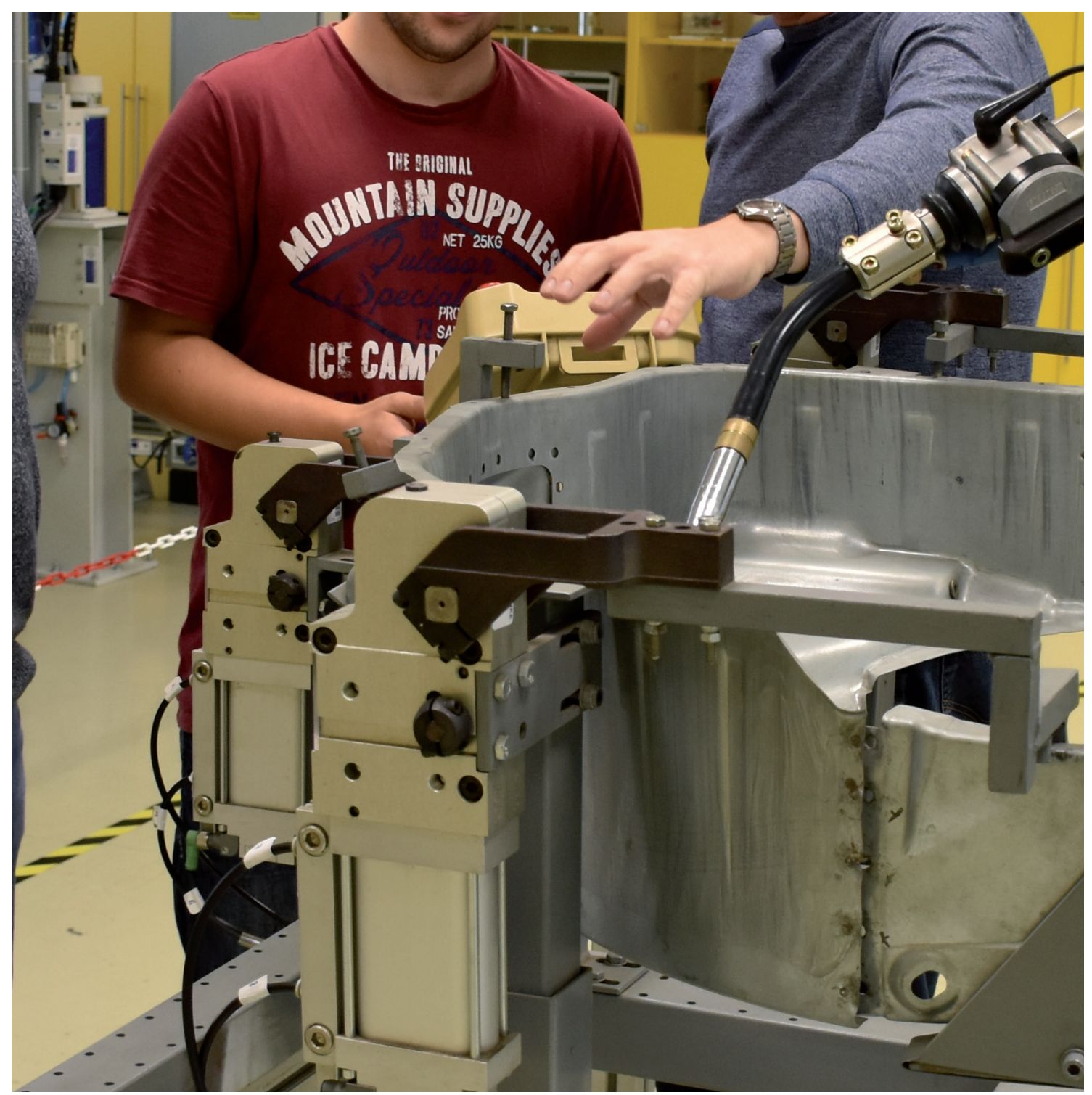

